\title{
O "30 de Maio": uma rebelião em Mato Grosso e a região de fronteira entre o Brasil e a Bolívia
}

\author{
The "May 30th": a rebellion in Mato Grosso and the border \\ region between Brazil and Bolivia
}

Ernesto Cerveira de Sena*

\begin{abstract}
Resumo
o "30 de Maio" foi uma rebelião ocorrida em Mato Grosso, durante o Período Regencial, tendo como principal alvo os portugueses "adotivos". A partir desse movimento, novos grupos políticos surgiram na província, porém as repercussões foram além da baixada cuiabana, influenciando o governo central a transigir com as lideranças locais. Outro desdobramento importante foi a relação com a Bolívia, pois foi para a região de fronteira entre o Império e a República boliviana que fugiram alguns dos acusados de participar da rebelião. Os fugitivos passaram, então, a ser motivo de disputa diplomática, enquanto os dois países se preparavam para estabelecer uma linha divisória entre ambos que passaria, mais cedo ou mais tarde, na então indefinida zona fronteiriça, separando as duas jurisdições, como característica dos novos Estados nacionais. Essa região não delimitada entre o Brasil e a Bolívia era lugar considerado pouco povoado. Os que fugiram para lá, então, participavam de estratégias de colonização, além de serem trunfo para futuros acordos territoriais. Assim, essa região fronteiriça apresentava demandas próprias, não sendo simples caixa de ressonância das capitais de seus países, embora, como área limítrofe, fosse parte dos interesses das autoridades locais e nacionais.
\end{abstract}

Palavras-chave: Região de fronteira. Mato Grosso. Santa Cruz de la Sierra. Rebelião Regencial.

\section{Abstract}

The "May 30th" was a rebellion that occurred in Mato Grosso State, during the Regency Period, having as main target the Portuguese "adoped". From this movement, new political groups have emerged in the province. But the

* Doutor em História pela Universidade de Brasília. Professor da Graduação e da Pós-Graduação em História da Universidade Federal de Mato Grosso. A pesquisa obteve apoio financeiro do CNPq. Pesquisa as relações centro-periferia no Brasil Império e as questões de fronteira com a Bolívia. E-mail: ernesto. sena@gmail.com 
repercussions were beyond Cuiabá's hinterland, influencing the central government to come to a compromise with the local leaders. Another important unfolding was the relationship with Bolivia, because those accused of participating in the "May 30th" had fled for border region between the Empire of Brazil and the Bolivian Republic . The fugitives, then, began to be a cause of diplomatic dispute, while the two countries were poised to establish a dividing line between them that would, sooner or later, in the undefined border region, separate both jurisdictions, as characteristics of the new national States. This region does not bounded between Bolivia and Brazil was a place considered little occupied. The fugitives then participated in strategies of colonization, in addition to being an asset for future territorial arrangements. Thus, the border region had its own demands not being a simple ressonance box of their countries decision centers, although, as a borderline area, it was part of the interests of the national authorities.

Keywords: Border zone. Mato Grosso. Santa Cruz de la Sierra. Rebellion Regency.

O "30 de Maio" foi uma rebelião ocorrida em Mato Grosso durante o Período Regencial, tendo como principal alvo os portugueses "adotivos". A partir desse movimento, novos grupos políticos surgiram na província. As repercussões, porém, foram além da baixada cuiabana, influenciando o governo central a transigir com as lideranças locais. É importante destacar que a relação com a Bolívia também foi afetada, pois foi para a região de fronteira entre o Império e a República boliviana que alguns dos acusados de participar do "30 de Maio" fugiram. Um dos principais acusados de assassinar um dos líderes do movimento antilusitano também se estabeleceu nessa zona fronteiriça. Assim, esses fugitivos passaram a ser motivo de disputa diplomática, enquanto os dois países se preparavam para estabelecer uma linha divisória entre ambos que passaria, mais cedo ou mais tarde, justamente na então indefinida área de fronteira, separando o lugar em duas jurisdições, como característica dos novos Estados nacionais.

A região não delimitada entre a Bolívia e o Brasil (que seria definida juridicamente somente em 1867) era lugar considerado pouco povoado e de tênue controle governamental. Os que fugiam ou se estabeleciam lá, então, acabavam participando de estratégias de colonização, haja vista os constantes reclames de falta de gente para forjar uma posse de terra, ao mesmo tempo que, sendo ocupada, poderia ser reivindicada pelos países como posse "legítima" de seu território. Assim sendo, também poderiam ser trunfos para futuros acordos territoriais entre os países, que aconteceriam inevitavelmente. 
O “30 de Maio": uma rebelião em Mato Grosso e a região de fronteira entre o Brasil...

As famosas rebeliões do Período Regencial brasileiro, como já foi mostrado pelo historiador Marcelo Basile, foram bastante heterogêneas, seja em relação aos seus atores - que poderiam ser desde comerciantes, escravos rebelados e soldados rasos até oficiais de alta patente, além de representantes das elites políticas -, seja em relação aos seus motivos, que não se reduziam apenas à falta de um monarca em exercício no momento em que o país era governando por Regências. ${ }^{1}$ Algumas rebeliões, classificadas como "do Período Regencial", até mesmo extrapolaram em vários anos o fim desse tipo de governo, como é o caso da Farroupilha. A assunção de D. Pedro II não significou que os ânimos se acalmariam automaticamente. Uma pesquisa mais focalizada sobre Mato Grosso mostra que a tensão continuou forte no decorrer da década de 1840, mesmo depois das chamadas leis "centralizadoras" (que não centralizaram como se previa, se queria ou se propagou), e revela que o trato com os grupos locais por parte do governo central foi de total cautela, com o intuito de evitar novas irrupções de descontentamento. ${ }^{2}$ De maneira semelhante, a conhecida Farroupilha também estendeu seus enfrentamentos com o Império até a década de 1840, mas, entre tantas diferenças entre a rebelião ocorrida em Mato Grosso e a República instalada nas partes meridionais do Brasil, podemos destacar que a tensão entre a primeira e o governo central se situou mais na possibilidade de uma nova explosão de violência que atingiria as elites locais, enquanto que os "farroupilhas" de fato enfrentaram o poder central com armas durante uma década, o que contribuiu para inúmeras representações sobre o "gaúcho", especialmente diferenciando-o do "restante" do país. ${ }^{3}$ O mesmo não podemos dizer do movimento do "30 de maio" em Cuiabá, que não se tornou "mito" que identificasse o "caráter" e a "distinção" dos habitantes de Mato Grosso, pelo contrário, como veremos. No entanto, o fato de ambos lugares, o oeste e o sul do Império, estarem em áreas fronteiriças os tornava lugares estratégicos para as relações internacionais, embora a parte meridional do Império, em comparação com Mato Grosso, fosse área em que as contendas com estrangeiros requeressem esforços militares e civis muito mais concentrados.

${ }^{1}$ BASILE, M. O laboratório da nação: a era regencial (1831-1840). In: SALLES, R.; GRINBERG, K. O Brasil Imperial: 1831-1889. V. II. Rio de Janeiro: Civilização Brasileira, 2009.

${ }^{2}$ SENA, E. C. de. Entre anarquizadores e pessoas de costumes: a dinâmica política nas fronteiras do Império Mato Grosso (1834-1870). Cuiabá: Carlini\&Caniato/EdUFMT, 2009.

${ }^{3}$ PESAVENTO, S. J. Uma certa Revolução Farroupilha. In: SALLES, R.; GRINBERG, K. O Brasil Imperial: 18311889. Rio de Janeiro: Civilização Brasileira, 2009. vol. II. 
Ernesto Cerveira de Sena

\section{O 30 de maio de 1834}

A forma escolhida para governar e construir o novo país foi a de um governo que levasse em conta as principais elites locais, maneira tida não só como a mais viável de manter a estabilidade diante das muitas demandas de uma nova entidade política, mas também a que poderia fazer frente aos vários desafios de um país que não conseguia se perceber sem o trabalho escravo, que se baseava nas riquezas da agricultura e no qual as extensas terras habitadas por grupos indígenas eram cobiçadas pelos que desejavam expandir tanto o poder econômico como o político pelos interiores do Império.

Foi nesse cenário que, em 1834, em Mato Grosso, ocorreu a rebelião que logo seria chamada de " 30 de Maio" pelos que viveram o momento. Posteriormente, a historiografia daria o nome de "Rusga", designação que significa "simples contenda", talvez em uma tentativa de amenizar as interpretações sobre os violentos conflitos dentro do próprio território brasileiro, em especial, Mato Grosso, omitindo pelo próprio nome os agravos que aconteceram. Como mostra o historiador Marco Morel, ${ }^{4}$ desde o Primeiro Reinado, em um crescendo durante o Segundo Reinado até tornar-se lugar-comum na República, os discursos das autoridades e visões históricas procuravam assinalar a "índole pacífica do povo brasileiro". Nesse sentido, não é difícil encontramos nos relatórios de presidentes de província especificando a "índole pacífica" dos "mato-grossenses", ao mesmo tempo em que estudos mais pormenorizados apontam a violência, tanto a física quanto a simbólica, permeando a sociedade oitocentista ${ }^{5}$.

Quando, nesse ano, estourou o movimento de "30 de Maio", já havia vários sinais do potencial explosivo da província fronteiriça, com motins e sublevações de soldados em várias guarnições desde, pelo menos, a década de 1820. A insatisfação com a carestia e os soldos atrasados eram fatores motivadores para insubordinações de militares, o que deixava em constante tensão as cidades e os povoados. ${ }^{6}$ Por outro lado, havia uma disputa entre as elites políticas de Cuiabá e de Vila Bela (ou cidade de Mato Grosso) que se arrastava por décadas. Essa última tinha sido criada para ser a capital da capitania, projetando-se sobre o que consideravam "domínios espanhóis", em uma tentativa de assegurar posse frente à Coroa espanhola, em meio a

\footnotetext{
${ }^{4}$ MOREL, M. O período das Regências (1831-1840). Rio de Janeiro: Jorge Zahar, 2003.

${ }^{5}$ Entre outros, ver CORREA, V. B. História e Violência de um “povo armado”. In: Projeto História, São Paulo, n. 39, pp. 57-73, jul/dez. 2009. Ver também MACHADO FILHO, O. Ilegalismo e Jogos de Poder: um crime célebre em Cuiabá e suas verdades jurídicas: 1840-1880. Cuiabá: Ed. UFMT, 2008.

${ }^{6}$ CORRÊA, V. B. História e violência em Mato Grosso, 1817-1840. Campo Grande: Ed. UFMS, 2000.
} 
O “30 de Maio": uma rebelião em Mato Grosso e a região de fronteira entre o Brasil...

muitos ataques indígenas, procurando defender seus territórios. Mesmo assim, desde a descoberta de quantidade considerável de metais preciosos no início do século XVIII, muitos se animavam a se mudar para lá, podendo até mesmo contar com incentivos estatais para se fixarem na região. ${ }^{7}$

Cuiabá, por outro lado, apesar de ter sido preterida na escolha da capital da capitania, ia se configurando como o principal entroncamento econômico regional e suas elites pretendiam que se tornasse também o centro político e administrativo. Essa reivindicação ficou mais contundente quando houve a convocação das Cortes em Lisboa, momento em que representantes das províncias do Brasil deveriam se apresentar para participar desse momento constituinte. Foi aí que se configurou mais intensamente a disputa entre Vila Bela e Cuiabá. Os dois lugares haviam formado juntas governativas com a deposição do capitão-general, atendendo à adesão às Cortes em Portugal. Como mostra Lima, o primeiro lugar vinha sofrendo com a mudança da geopolítica portuguesa em relação ao Mato Grosso desde fins do século XVIII, quando os lusos acharam mais promissor investir no fortalecimento da área fronteiriça nos afluentes do rio Paraguai, que corriam para o sul, no lugar de investirem na região do rio Guaporé, componente da bacia amazônica, em cuja margem estava Vila Bela. Na prática, já havia cerca de quatro governos de capitães-generais em que o comando da capitania - depois transformada em província - era exercido principalmente em Cuiabá, demonstrando a mudança de estratégia lusa em relação à região. ${ }^{8} \mathrm{Com}$ argumentos persuasivos, que iam desde a insalubridade - que na verdade era vista por viajantes não só em Vila Bela, mas também em Cuiabá e outras partes de Mato Grosso ${ }^{9}$-, ao maior número de habitantes e comarcas, as elites políticas cuiabanas se uniram contra o estatuto de capital de província na cidade de Mato Grosso (Vila Bela), querendo elevar o status de sua localidade, ao mesmo tempo que angariavam simpatias políticas em seu próprio lugar de moradia.

Assim, tanto Vila Bela como Cuiabá tiveram seus próprios representantes no movimento Vintista de Portugal, e depois, com a independência, procuravam a aceitação da capital do Império instalada no Rio de Janeiro. ${ }^{10}$

${ }^{7}$ SIQUEIRA, E. M. História de Mato Grosso: da ancestralidade aos dias atuais. Cuiabá: Entrelinhas, 2002.

${ }^{8}$ LIMA, A. N. Mato Grosso e a geopolítica da independência (1821-1823). In: Territórios \& Fronteiras, Cuiabá, v. 5, n. 2, p. 3-31, jul./dez. 2012.

${ }^{9}$ ANZAI, L. C. Doenças e práticas de cura na capitania de Mato Grosso: o olhar de Alexandre Rodrigues Ferreira. Tese (Doutorado) - Instituto Central de Ciências, Universidade de Brasília, Brasília, 2004.

${ }^{10}$ LIMA, A. N. Mato Grosso e a geopolítica da independência (1821-1823). In: Territórios \& Fronteiras, Cuiabá, v. 5, n. 2, p. 3-31, jul./dez. 2012, p. 5 . 
Nessa luta pela transferência efetiva da sede de governo, se destacaram fazendeiros, comerciantes e detentores de cargos públicos como Fernando Corrêa da Costa, Jerônimo Joaquim Nunes, André Gaudie Ley e Poupino Caldas. Somente o segundo era português de nascimento, mas consolidada a supremacia cuiabana ante Vila Bela, começou a cisão dentro dessa elite política cuiabana, com destaque especial para a liderança exercida por Poupino Caldas, oficial de milícias. Aliando-se com o cirurgião Patrício da Silva Manso, esse grupo fundou a Sociedade dos Zelosos da Independência, espelhando-se em várias outras que se distribuíam pelo Império. ${ }^{11}$ Essa sociedade preconizava, sobretudo, a expulsão dos portugueses da província e a desapropriação de seus bens e benefícios em linhas comerciais.

Poupino tinha aceitação e influência entre os homens de armas, principalmente entre os de baixa patente, que volta e meia se rebelavam por melhores condições de trabalho. Ele valeu-se dessa sua projeção para conseguir fazer vitorioso o movimento de seu grupo antilusitano, mas que, na verdade, era contrário também aos outros da elite cuiabana que vinham ocupando os principais postos governamentais. Assim, no dia 30 de maio de 1834, com parte da população descontente e raivosa, os "zelosos" ameaçaram colocar fim aos portugueses. Poupino fazia parte da junta governadora, sendo o único dela que apoiava a manifestação que se avolumava e ameaçava a radicalização. Assim, o Conselho de Governo resolveu passar o comando da província para o próprio Poupino, possivelmente como uma estratégia para conter a rebelião. Mas nada adiantou. Saques, torturas e assassinatos foram praticados impetuosamente em Cuiabá e depois se alastraram para outras partes da província. Como governante, Poupino saiu em diligência para controlar os rebelados. ${ }^{12}$ Satisfeito, logo escrevia para o governo central afirmando que tudo estava em paz, graças à saída de "todos adotivos dissidentes da ordem" da província. ${ }^{13}$ Portanto, ele não só se colocava como a pessoa que estava defendendo os conflitos, como, nesse momento, apontava para os próprios portugueses, que tinham sido destroçados, como culpados pelo ocorrido.

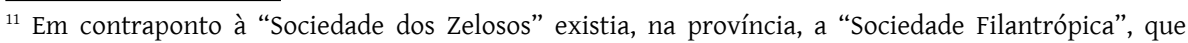
agregava os portugueses e outras pessoas ligadas ao grande comércio exportador/importador. SIQUEIRA, E. M. Op. cit., p. 88. Na verdade, existiam muitas sociedades desse tipo espalhadas pelo Brasil, antes de aparecerem os partidos políticos. Ver GUIMARÃES, L. M. P. Liberalismo moderado: postulados ideológicos e práticas políticas no período regencial (1831-1837). In: GUIMARÃES, L. M. P.; PRADO, M. E. (Orgs.). 0 liberalismo no Brasil imperial: origens, conceitos e práticas. Rio de Janeiro: Revan, 2001. p. 73-102.

${ }^{12}$ SIQUEIRA, op. cit., p. 89-90.

${ }^{13}$ Arquivo Nacional. IJJ (9) 505. Poupino Caldas para A. Pinto Chinchôrro da Gama. Cuiabá, 3 de junho de 1834.
} 
O “30 de Maio": uma rebelião em Mato Grosso e a região de fronteira entre o Brasil...

Com a chegada do primeiro presidente de província, Antônio Pedro de Alencastro, Poupino Caldas tornou-se um dos principais apoiadores do novo governo. Com o novo governante, conseguiu cadeiras para pessoas de seu grupo na recém-inaugurada Assembleia Legislativa, mas ao mesmo tempo delatava ex-aliados que teriam participado do "30 de Maio". Várias pessoas foram presas, no entanto, estava na vista de todos que Poupino traíra seus antigos aliados "zelosos", além da população menos expressiva econômica e politicamente que antes tinha lhe confiado apoio. Assim sendo, estava jurado de morte, motivo pelo qual passou a morar sob escolta em quartel.

Com a saída de Alencastro, Poupino Caldas recebeu de maneira hostil o novo presidente Pimenta Bueno, futuro marquês de São Vicente. Se a intenção do primeiro era demonstrar força na província, o resultado acabou sendo o oposto, e vendo-se ameaçado de processos e prisão caso não deixasse logo Mato Grosso. ${ }^{14}$ Enquanto se despedia, foi assassinado por algum de seus vários desafetos. Entre esses, certamente havia os cinco tidos como líderes do movimento, que mesmo mandados para responder processo na Corte, não chegaram a cumprir pena, ${ }^{15}$ enquanto outros, menos graduados socialmente, ou fugiram ou foram mandados para prisões em várias partes da província.

Em 1837, os 17 acusados de promover o "30 de maio" que estavam na cadeia da ex-capital de Mato Grosso, Vila Bela, mataram o carcereiro, se apropriaram de armamentos que existiam no quartel e rumaram para a Bolívia, sem que ninguém pudesse detê-los. A partir desse momento começou uma série de diálogos entre as autoridades da Bolívia e as do Império e, mais especificamente, entre os governantes do departamento de Santa Cruz, o que inclui a província vizinha de Chiquitos, e os representantes da província de Mato Grosso. Os fugitivos entraram na pauta de discussões entre os dois países, mas, na verdade, passaram a fazer parte de uma discussão maior sobre limites territoriais e as relações que os dois novos países vizinhos deveriam estabelecer.

\section{Repercussões do "30 de maio" na região de fronteira com a Bolívia}

Se o próprio "30 de Maio", ou a "Rusga", foi pouco estudado nas universidades em comparação a outros movimentos do Período

\footnotetext{
${ }^{14}$ CORREA FILHO, V. História de Mato Grosso. Várzea Grande: Fundação Júlio Campos, 1993.

${ }^{15}$ SIQUEIRA, op. cit., p. 91.
} 
Regencial ${ }^{16}$ ocorridos em outras partes do Brasil, o seu alcance, que ultrapassou os limites fronteiriços, foi menor ainda, para não dizer completamente inexistente. Os debates entre as autoridades da Bolívia e do Brasil sobre os fugitivos acarretariam em uma série de interpretações sobre soberania, território e reciprocidade entre países, o que, de certa forma, somente começaria a ser resolvido com o tratado de 1867, que inclusive regulamentaria a extradição de pessoas procuradas pela justiça de seus países.

Primeiramente, é interessante notar que, nos primeiros anos do Império brasileiro, atenção deste estava voltada para o reconhecimento de sua independência frente, especialmente, aos países europeus, estabelecendo uma série de tratados. Ao mesmo tempo, o Império se digladiava principalmente contra Buenos Aires, "herdando" uma guerra do período de D. João VI, que resultaria na criação do Uruguai, em 1827, sob arbitragem da Inglaterra, procurando neutralizar a influência dos principais contendores no estratégico rio da Prata. ${ }^{17}$

Já durante as Regências, a política externa do Império procurou voltar-se mais para outros países americanos, com o fim de estabelecer acordos diplomáticos, tratando de comércio, navegação, "amizade" etc. Mas tal intento, como mostra Santos, não foi uma linha contínua, nem um projeto sólido e coerente de política externa, devido não somente às várias conturbações pelas quais passava internamente o Brasil e os países sul-americanos nas primeiras décadas após suas independências, como também ainda era da Europa que vinham as principais mercadorias importadas. Dessa maneira, segundo Santos, se firmaria uma política mais coesa voltada para o exterior, somente na segunda metade do século XIX. ${ }^{18}$

Mesmo hesitando em estabelecer um projeto de relações internacionais, o Império enviou vários representantes das repúblicas da América do Sul para a Bolívia ainda na década de 1830, quando várias rebeliões como a "Rusga" aconteciam no Brasil. o país vizinho, por sua vez, também não era exemplo de estabilidade política, o que, igualmente, não o impedia de enviar seus emissários diplomáticos ao Rio de Janeiro. ${ }^{19}$

\footnotetext{
${ }_{16}$ Podemos contar com os seguintes estudos: SIQUEIRA, E. M. A Rusga em Mato Grosso: edição crítica de documentos históricos. Dissertação (Mestrado) - Faculdade de Filosofia, Letras e Ciências Humanas, Universidade de São Paulo, São Paulo, 1992. AGUIAR, P. F. Uma sedição no sertão: o 30 de maio de 1834 em Cuiabá e suas ressonâncias. Dissertação (Mestrado) - Instituto de Ciências Humanas e Sociais, Universidade Federal de Mato Grosso, Cuiabá, 2012. Atualmente, André Nicácio de Lima desenvolve uma tese de doutorado, na Universidade de São Paulo, especificamente sobre o movimento.

${ }^{17}$ CERVO, A. L.; BUENO, C. História da Política Exterior do Brasil. Brasília: UnB, IBRI, 2002.

${ }^{18}$ SANTOS, L. C. V. G. O Império e as Repúblicas do Pacífico: as relações do Brasil com Chile, Bolívia, Peru, Equador e Colômbia (1822-1889). Curitiba: Editora UFPR. 2002.

${ }^{19}$ SOARES, T. História da formação das fronteiras do Brasil. Rio de Janeiro: Conselho Federal de Cultura, 1972.
} 
O “30 de Maio": uma rebelião em Mato Grosso e a região de fronteira entre o Brasil...

Seria com o país fundado por Sucre que o Império teria a maior fronteira a ser delimitada. Eram praticamente os "limites" do departamento boliviano de Santa Cruz e a província de Mato Grosso. No entanto, esses "limites" estavam longe de serem definidos pelos dois novos Estados nacionais. Os antigos tratados coloniais não eram fontes seguras para dizer onde começaria um país e terminaria o outro na Ibero-América, como se fossem "heranças" incontestáveis deixadas pelos colonizadores portugueses e espanhóis. Na verdade, existia uma região ou zona fronteiriça entre os novos países, onde as jurisdições não estavam estabelecidas formalmente e era pouco controlada pelas autoridades, sendo algumas partes mais conhecidas e habitadas, outras menos, quando não totalmente ignoradas naquele momento pelas autoridades governamentais. ${ }^{20}$

O primeiro contato oficial entre os dois países - que começaram a se formar na década de 1820 - foi justamente quando findavam as guerras de independência comandadas por Bolívar, as quais teriam como um dos resultados a criação da Bolívia. O então governador realista da província de Chiquitos, Sebastián Ramos, que já tinha relações com algumas pessoas proeminentes de Vila Bela, pediu a anexação de sua área administrativa ao Império brasileiro. Antes de esperarem resposta do governo central do Império, uma tropa saída de Mato Grosso "tomou posse" de Chiquitos, por pouco tempo, até que vários fatores corroboraram para a sua retirada, desde uma insurreição indígena, ameaças de generais "libertadores" de travar guerra contra o Império, além do próprio arrependimento da iniciativa de anexação pela cúpula política da capital de Mato Grosso. De suma importância também foi a carta de D. Pedro rechaçando tal invasão. ${ }^{21}$

De toda forma, quando a tropa saiu, o próprio governador de Chiquitos migrou para a região de fronteira, fugindo das tropas independentistas de Sucre. Além dele, muitos índios e outros criollos seguiram o mesmo rumo. ${ }^{22}$ O governo de Mato Grosso tratou de acomodá-los.

Ao governo de Mato Grosso interessava povoar várias áreas. Assim, as autoridades brasileiras fizeram vários esforços para que os indígenas

${ }^{20}$ Ver SENA, E. C. de. De colônias a início dos Estados nacionais: considerações sobre as fronteiras entre a Bolívia e o Brasil. Territórios \& Fronteiras, Cuiabá, v. 5, 2012, p. 114-130; ver também MAGNOLI, D. O Corpo da Pátria: imaginação geográfica e política externa no Brasil (1808-1912). São Paulo: Unesp/Moderna, 1997.

${ }^{21}$ SECKINGER, R. L. La cuestión de Chiquitos: una breve crisis en las relaciones boliviano-brasileñas. Revista de la Universidad Gabriel René Moreno, Santa Cruz de la Sierra, n. 39-40, 1985.

${ }^{22}$ Ibidem, p. 12. 
migrados de Chiquitos se acomodassem em território considerado brasileiro, ${ }^{23}$ além de proporcionarem um lugar para Ramos se arranchar perto de Vila Bela, na região de Salinas do Jauru. Eles não seriam "devolvidos" para o novo governo que se formava na Bolívia. Pelo contrário, havia uma política de atração de pessoas que pudessem viver na região fronteiriça. A situação do governador começou a mudar na década de 1830, quando passou a se declarar boliviano republicano. Mas como as áreas e a jurisdição na zona de fronteira estavam indefinidas, o máximo que os representantes do Império conseguiram fazer foi que Sebastián Ramos e os seus camaradas mudassem sua rancharia para outras partes..$^{24}$

A Bolívia não faria diferente em relação a quem migrasse para lá, inclusive procurando povoar essa mesma região de fronteira (embora com menos sucesso) fornecendo títulos de terras, por exemplo, o que causava indignação nas autoridades brasileiras ${ }^{25}$, ou tentando colonizar áreas que dessem acesso ao rio Paraguai.

Nesse sentido, em consequência do "30 de Maio", autoridades bolivianas se dispuseram a auxiliar um grupo de brasileiros, caso desejassem migrar para o seu país, já que estavam sentindo-se inseguros no lado oriental da fronteira, diante dos violentos ataques em Mato Grosso. Essa disposição começou (ou ficou explícita) quando o comandante de armas de Mato Grosso, Joaquim José de Almeida, escreveu para o governador Marcelino de la Peña, para que recebesse bem os que saíssem do Império para a província boliviana, pois "eis que o gênio do mal" fez "inundar de sangue Cuiabá", e muitos se sentiam ainda aflitos. Assim, dizia: “[...] os cidadãos perseguidos pelas mais cruentas camadas acharão nos vossos braços um asilo carinhoso, na vossa cidade o templo da paz, na vossa refletida filantropia aqueles socorros, que o desgraçado tem o direito de esperar de corações bem formados". ${ }^{26}$

\footnotetext{
${ }^{23}$ Dessa maneira, por exemplo, um militar tomava todas as providências necessárias para transporte e acomodação de dezenas de indígenas que estavam na zona de fronteira para uma área reservada a eles pelas autoridades brasileiras. Arquivo Público de Mato Grosso (APMT). Caixa 1826. Comandante Constantino Ribeiro da Fonseca para capitão ajudante Vicente Rebelo Leite Pereira. 18 de setembro de 1826.

${ }^{24}$ Arquivo Público de Mato Grosso (APMT). Registro de Correspondência com outras Províncias e a Bolívia (RCPB). Pimenta Bueno para Coronel D. Pedro José Urtuby, Governador e Chefe Superior da Província de Chiquitos. Cuiabá, 7 de novembro de 1837.

${ }^{25}$ APMT. RCPB. Antônio Pimenta Bueno para Duarte da Ponte Ribeiro, encarregado de Negócios do Brasil em Chuquisaca. Cuiabá, 7 de novembro de 1837.

${ }^{26}$ Museo de História y Archivo Histórico de Santa Cruz. (MHAHSC). Prefectura del Departamento de Santa Cruz. Caja 1/16. Comandante de Armas Joaquim José de Almeidapara Governador Marcelino de la Peña. Mato Grosso, 3 de julho de 1834.
} 
O “30 de Maio": uma rebelião em Mato Grosso e a região de fronteira entre o Brasil...

O governador de Chiquitos respondeu, lastimando-se das "desgracias de um pueblo amigo y hermano", e que em decorrência da "íntima amistad" que a Bolívia tinha com o Brasil,

"tomé desde luego las más activas providencias para que pela parte del Jauru, el Marco y otros puntos de contacto se protegiesen à todos los desgraciados que pudieron escapar de sus asesinos mandando que fuesen recogidos y asilados em el seno de la amistad". ${ }^{27}$

Não temos notícia dessas pessoas que, com medo da continuação das agressões, se refugiariam na Bolívia. No entanto, pelos registros encontrados, as que conseguiram asilo na República foram justamente as que cometeram matanças decorrentes da rebelião do "30 de Maio". Ou seja, quando os 17 fugitivos de Vila Bela passaram pela zona fronteiriça, foram se ater com autoridades bolivianas e por lá ficaram. Os governantes brasileiros logo fizeram várias representações para que fossem extraditados para o Brasil.

Desse modo, o presidente Antônio Pimenta Bueno, que mais tarde ocuparia muitos cargos no Império, inclusive o de ministro das Relações Exteriores, escrevia para a província de Chiquitos afirmando que, fosse pelo "Direito das Gentes" - uma forma consuetudinária que regularia relacionamentos, inclusive entre países ${ }^{28}$-, fosse pelo Direito Positivo expresso no "Tratado de $1^{\circ}$ de outubro de 1777 que prevalece entre o Brasil e a Bolívia", exigia a restituição dos criminosos por parte do governo de Chiquitos. Ponderava em sua carta que as "nações" normalmente não eram obrigadas a extraditar pessoas estrangeiras que procuravam asilo em outros países, no entanto, isso não poderia ser seguido para um caso como esse, pois tratava-se de cruéis assassinos, que até mesmo poderiam colocar em perigo o departamento de Santa Cruz, do qual a província de Chiquitos fazia parte. Dessa maneira, descrevia os horrores cometidos, como a prática de 33 homicídios, com "refinada crueldade", tais como lançar fogo em pessoas ainda semivivas, cortar-lhes as orelhas e "partes pudendas", atravessar-lhes os

${ }^{27}$ MHAHSC. Prefectura del Departamento de Santa Cruz. Caja 1/16. El gobierno de la Província de Chiquitos al Comandante de Armas Joaquim José de Almeida - Santa Ana, 26 de Julio de 1834.

${ }^{28} \mathrm{O}$ "Direito da Gentes" tratava de princípios não necessariamente sistematizados, mas que foram de grande valia na época das independências na América Latina, pois preconizavam a soberania exclusivamente dos povos quando estes não se percebessem mais representados pelo rei. Também poderiam ser parâmetro para as relações entre dois países ou unidades políticas. Em geral, rogavam a não intromissão de um país em negócios internos de outro. Concorria com o Direito Positivo, elaborado principalmente a partir das assembleias constituintes do século XIX. Ver CHIARAMONTE, J. C. Fundamentos intelectuales y políticos de las independencias: notas para una nueva historia intelectual de Iberoamérica. Buenos Aires: Teseo, 2010. 
"ouvidos com baionetas", além de obrigar "as famílias dos desgraçados a pôr luminárias, proibindo que se desse sepultura aos cadáveres". Portanto, se era facultado às "nações cultas" a devolução de fugidos de outros países, nesse caso não poderia ser concebido, pois eram caracterizados pela "qualidade e frequência de delitos", que "ameaçam a segurança comum da sociedade humana". 29

O governante de Mato Grosso ainda pedia a restituição das armas e munições como reciprocidade, ao lembrar que um animal roubado de um habitante de Santo Coração de Chiquitos tinha sido devolvido por autoridades brasileiras. ${ }^{30}$ Por fim, ameaçava que a permanência de tais réus na parte boliviana "só serviria para cortar as relações de comércio que devem [...] cada vez mais ir crescendo entre as duas províncias, como pedem os recíprocos interesses". ${ }^{31}$ Desse modo, se não havia uma base jurídica que pudesse apoiar as relações entre as duas províncias, recorria, então, à ameaça de corte das relações comerciais, mesmo sem nunca ter sido possível um grande ordenamento oficial sobre tal atividade entre Mato Grosso e Chiquitos desde o período colonial..$^{32}$

Apesar disso, se Pimenta Bueno recorria ao tratado de 1777 (Santo Ildefonso) estabelecido pelas ex-metrópoles como alguma maneira legal de conseguir que fosse feita a extradição dos fugitivos, logo ele mesmo aconselharia o representante brasileiro, Duarte da Ponte Ribeiro, em missão diplomática na Bolívia, para que desconsiderasse firmemente o mesmo acordo metropolitano, pois poderia colocar em perigo estabelecimentos construídos a oeste do rio Guaporé, como Casalvasco, inaugurado na década de 1780, além de outros que interessavam ao novo país manter, mas que estariam fora dos limites acordados por Portugal e Espanha. ${ }^{33}$

Assim, se o acordo do tempo de colônia poderia ser a base de negociações sobre fronteiras e "amizade", como se dizia na linguagem diplomática, passou a ser desqualificado pelos representantes brasileiros

\footnotetext{
${ }^{29}$ APMT. RCPB. José Antônio Pimenta para D. Marcelino de la Peña. Governador e Superior da Província de Chiquitos. Cuiabá, 8 de março de 1837.

${ }^{30}$ Outro precedente tinha sido a devolução de alguns pertences das igrejas de Chiquitos levados por Sebastián Ramos, em 1825, quando se instalou na zona fronteiriça, sob os auspícios dos governantes de Mato Grosso. Ver SECKINGER, Ron Leroy. La cuestión de Chiquitos: una breve crisis en las relaciones boliviano-brasileñas. Revista de la Universidad Gabriel René Moreno, Santa Cruz de la Sierra, n. 39-40, 1985, p. 17.

${ }^{31}$ Idem.

${ }^{32}$ AMADO, J.; ANZAI, L. C. Anais de Vila Bela (1734-1789). Cuiabá: Ed. UFMT, 2006.

${ }^{33}$ APMT. RCPB. Pimenta Bueno para Duarte da Ponte Ribeiro, Encarregado dos Negócios do Brasil em Chuquisaca. Cuiabá, 5 de maio de 1837.
} 
O “30 de Maio": uma rebelião em Mato Grosso e a região de fronteira entre o Brasil...

como parâmetro de entendimento entre os dois países. O "Direito das Gentes" também era muito citado pelas autoridades de ambos os lados da fronteira, sem que fossem citados nenhum de seus autores expoentes, como se usava nos tempos das guerras pela independência em relação à Espanha ${ }^{34}$, cabendo também interpretações diversas por ambas as partes - desde o direito à "propriedade dos escravos" que tinham fugido para a Bolívia, por parte das autoridades imperiais, ao "direito de liberdade" de todo ser humano, inclusive dos negros que estavam na região de fronteira, por parte dos homens de governo bolivianos, mesmo que tal mudança de status não viesse efetivamente a acontecer, pois muitos habitantes da República entregavam cativos fugidos nos pontos fronteiriços em busca de recompensas dadas por habitantes de Mato Grosso. ${ }^{35}$

De toda forma, a região de fronteira, indefinida quanto a limites de territorialidade e atuação dos novos Estados nacionais, não deixava de se apresentar como lugar oportuno não só para escravos fugidos tentarem sua liberdade nessa área, mas também para outras pessoas que desafiavam a ordem jurídica de seu país. Assim, além dos 17 fugitivos, outro que teve participação efetiva no "30 de Maio" foi Antônio José Rodrigues, chamado de "facínora" pelas autoridades de Mato Grosso, que fugira quando começaram as prisões capitaneadas pelo presidente Antônio Pedro de Alencastro, secundado por Poupino Caldas, em uma franca atitude de traição aos seus antigos companheiros que o apoiaram na derrubada dos "bicudos".

Antônio José Rodrigues estava em "um ponto limítrofe da [...] nossa raia", dizia o chefe do Executivo em Mato Grosso, que solicitava que ele também fosse entregue às autoridades brasileiras. Do local onde estava, continuava a dar prosseguimento aos horrores do "30 de Maio", ao fazer chegar a Cuiabá "os maiores insultos, roubos", "fomentando as confusões e as intrigas" que poderiam prejudicar a "harmonia recíproca" que existiria entre a Bolívia e o Brasil. ${ }^{36}$

Mais de um ano depois, o presidente de província que substituiu Alencastro, Pimenta Bueno, insistia que Antônio José Rodrigues estava em posição irregular na zona fronteiriça e que as autoridades bolivianas

${ }^{34}$ CHIARAMONTE,J.C. Nación y Estado en Iberoamérica: el lenguaje político en tiempos de las independencias. Buenos Aires: Sudamericana, 2004.

${ }^{35}$ APMT. RCPB. José Antônio Pimenta Bueno para Duarte da Ponte Ribeiro, Encarregado dos Negócios do Brasil em Chuquisaca. Cuiabá, 11 de maio de 1838.

${ }^{36}$ APMT. RCPB. Antônio Pedro de Alencastro para Diogo de la Riva. Cuiabá, 24 de dezembro de 1835. 
deviam tomar alguma atitude. ${ }^{37}$ Mas seu governo em Mato Grosso não era uma continuação do antecessor. Com sua presença, iniciou-se um novo reordenamento nos grupos políticos provinciais. A ideia era formar um grupo que não fosse ligado nem a Poupino Caldas - e consequentemente aos ex-insurgentes -, nem à antiga elite cuiabana, capitaneada por Correa de Costa e Gaudie Ley. Nasceu, então, o partido que depois foi chamado de Liberal, elaborado, sobretudo, na articulação entre as regiões de Poconé, Vila Maria, Vila Bela e Diamantino, além de contarem com alguns cuiabanos que não tinham acesso a postos muito proeminentes. ${ }^{38}$

Como já nos referimos, foi justamente no período em que Pimenta Bueno era presidente de província em Mato Grosso que Poupino Caldas foi assassinado. Para as autoridades da província, entre alguns indiciados, um que muito provavelmente tinha sido responsável pelo assassinato era o morador da zona de fronteira, Antônio José Rodrigues, que para lá se dirigiu depois do "30 de maio".

De onde ele estava, conseguia fazer com que chegassem insultos "picantes e ameaçadores ${ }^{39 "}$ ao presidente que estava formando processo contra os participantes da rebelião de 1834, aproveitando-se de sua localização para agredir sem ser pego. Por outras vezes, entrava na província para causar alvoroço e depois retornava impunemente. Em uma dessas “entradas", Antônio José Rodrigues teria contratado um matador, na própria capital provincial, para dar cabo à vida de Poupino Caldas. Assim, Pimenta Bueno, em carta ao governador de Chiquitos, dizia que "não há prova no todo indubitável" de que Rodrigues tivesse sido o autor do assassinato. Haveria também outros rastros sobre sua autoria no crime, mas sem especificar na carta. Portanto, já não mais pedia para que fosse extraditado, como desde seu antecessor era solicitado, mas, sim, que fosse retirado da região de fronteira, interiorizando-se na Bolívia. ${ }^{40}$

A fuga para a Bolívia dos que participaram do "30 de Maio" tornou-se um dos principais assuntos internacionais, que, nesse momento, cabia aos próprios presidentes de província resolver. À evasão de procurados pela

\footnotetext{
${ }^{37}$ APMT. RCPB. José Antônio Pimenta Bueno para D. Marcelino de la Peña, Governador e Chefe Superior da Província de Chiquitos. Cuiabá, 10 de junho de 1837.

${ }^{38}$ SENA, E. C. de. Entre anarquizadores e pessoas de costumes: a dinâmica política nas fronteiras do Império Mato Grosso (1834-1870). Cuiabá: Carlini\&Caniato/Ed. UFMT, 2009. p. 49-98.

${ }^{39}$ APMT. RCPB. Antônio Pedro de Alencastro para Diogo de la Riva. Cuiabá, 24 de dezembro de 1835.

${ }^{40}$ APMT. RCPB. Antônio Pimenta Bueno para Marcelino de la Peña, Governador de Chiquitos. Cuiabá, 10 de junho de 1837.
} 
O “30 de Maio": uma rebelião em Mato Grosso e a região de fronteira entre o Brasil...

justiça estava relacionada também a concessão de terrenos que o governo de Chiquitos fazia a brasileiros, sendo um dos beneficiários o próprio indiciado por matar o coronel Poupino Caldas, José Rodrigues, que estava estabelecido nas Salinas do Jauru, área da região de fronteira ainda vista como pertencente à Bolívia, embora os países limítrofes ainda não houvessem entrado em acordo definitivo sobre a qual deles pertenceria tal área.

$\mathrm{Na}$ verdade, era normal considerar a zona fronteiriça como "vazia", ${ }_{4}$ e assim, tanto a Bolívia quanto o Brasil procuravam atrair para a sua área de influência pessoas que seriam "do outro lado" para colonizá-las, como foi o caso dos índios Chiquitano, referido anteriormente, e do rancho do ex-governador Ramos em dado momento. No entanto, quando as autoridades bolivianas procuram manter José Rodrigues na zona de fronteira (o que, com o tempo, poderia configurar indubitavelmente como território boliviano), não seria somente para tentar colonizar áreas tidas como "vazias" e que ainda estavam em litígio entre os dois países vizinhos. Era, também, para poder barganhar em um futuro tratado a respeito dos limites entre ambos os países, utilizando como trunfo a extradição de criminosos e escravos fugidos para a República. Como aponta Foucher, uma das características dos Estados nacionais que surgiram no século XIX era estabelecer linhas de fronteira, demarcando o espaço de atuação de cada $u^{42}$. $O$ estabelecimento de limites deveria acontecer em algum momento no futuro, após as independências, como prerrogativa da própria "identidade nacional" em construção $0^{43}$.

De toda forma, é interessante destacar que a Bolívia tinha seus interesses mais voltados para os outros países dos Andes e do Pacífico. Dessa maneira, chegou a formar uma confederação com o Peru, na década de 1830, e foi aliada dos peruanos em guerra contra o Chile, na década de 1870, tendo por consequência a perda de sua província litorânea ${ }^{44}$. O Império do Brasil também tinha sua atenção mais voltada para o litoral, porém um dos motivos para a guerra contra o Paraguai, em 1865, foi justamente a tentativa de

\footnotetext{
${ }^{41}$ Como mostra Pilar García Jordán, o termo "vazio" traduzia uma concepção segundo a qual ditas regiões permaneciam à margem das sociedades nacionais, posto que nesses territórios viviam numerosas populações indígenas não submetidas que, em discurso da época, eram "selvagens", "bárbaras", "nômades". GARCÍA JORDÁN, P. Cruz y arado, fusiles y discursos: la construcción de los Orientes en el Perú y Bolivia - 1820-1940. Lima: IFEA/IEP, 2001.

${ }^{42}$ FOUCHER, M. L'invention des frontières. Paris: F.E.D.N., 1986.

${ }^{43}$ FOUCHER, M. Obsessão por fronteiras. São Paulo: Radical Livros, 2009.

${ }^{44}$ KLEIN, H. S. O fim da sociedade colonial e a criação de uma nação independente (séculos XVIII e XIX). In: PAMPLONA, M. A.; MÄDER, M. E. (Orgs.). Revoluções de independências e nacionalismos nas Américas: Peru e Bolívia. Rio de Janeiro: Paz e Terra, 2010.
} 
assegurar a navegação para o interior do continente, acessando Mato Grosso pela bacia platina.

Assim, a Bolívia, em situações precárias no seu oriente e com pouca gente e recursos para colonizar a zona fronteiriça, continuou negando oficialmente a extradição de pessoas consideradas criminosas no Brasil. 0 máximo que realizou na questão dos fugitivos do "30 de Maio" foi devolver os armamentos tinham levado consigo ${ }^{45}$. No caso de Antônio José Rodrigues, o governo boliviano aceitou retirá-lo das Salinas do Jauru e enviá-lo para o interior da Bolívia, como fizera também em relação aos foragidos de Vila Bela, o que, para o presidente da época, na sua linguagem diplomática, era uma "prova de justiça e lealdade" e "razão para de novo firmar" a "obrigação de reciprocidade" 46 .

No entanto, apesar de as palavras das autoridades expressarem a "amizade" entre os vizinhos, não só as Salinas do Jauru seriam ocupadas por tropas brasileiras ${ }^{47}$ como os dois países eram vistos como possibilidades de articulações políticas pelos grupos locais, pelo menos desde a tentativa de anexação de Chiquitos por uma tropa de Mato Grosso e a fuga do ex-governador Sebastián Ramos para a zona fronteiriça entre os dois novos países.

Cabe aqui destacar que o cônego Silva Guimarães, um dos líderes liberais, entre o final da década de 1830 e início da de 1840, foi acusado de ter articulações com a Bolívia, propondo juntar Mato Grosso à República ${ }^{48}$. Acontecia que o então presidente, Ribeiro de Rezende, estava se confrontando fortemente com a Assembleia Legislativa. Assim, fazia uma série de desconsiderações em relação ao presidente da casa parlamentar local, que era o cônego, esperando alguma ajuda do governo central nos seus enfrentamentos contra os locais. No entanto, isso não aconteceu, sendo o principal oponente designado como presidente de província para substituí-lo.

Outro político acusado de ter o país vizinho em seus cálculos foi Manuel Alves Ribeiro, ${ }^{49} \mathrm{o}$ qual procuravam representar como o

\footnotetext{
${ }^{45}$ Arquivo Nacional. Pasta IJJ(9) 506. Antônio Pimenta Bueno para Duarte da Ponte Ribeiro, Encarregado dos Negócios do Brasil em Chuiquisaca. Cuiabá, 7 de novembro de 1837.

${ }^{46}$ APMT. RCPB. Antônio José Pimenta Bueno para Coronel D. Pedro José de Urtuby, Governador e Chefe Superior da Província de Chiquitos. Cuiabá, 10 de março de 1838.

${ }^{47}$ Archivo Biblioteca Nacional de Bolivia. MRREE - Brasil-Bolivia. António Vicente Peña para Ministro de Relaciones Exteriores de la República de Bolivia. Asunción, 5 de octubre de 1847.

${ }^{48}$ Arquivo Nacional. Pasta Estevão Ribeiro de Rezende para Manoel Antônio Galvão, Ministro do Império. Cuiabá, 16 de março de 1840.

${ }^{49}$ Arquivo Nacional. Pasta IJJ(9) 507. Joaquim José de Oliveira para Antônio Manoel de Campos Mello. Ministro da Justiça. Cuiabá, 29 de novembro de 1848. Notar que 1848 foi o ano em que os liberais de Pernambuco e de São Paulo se rebelaram.
} 
O “30 de Maio": uma rebelião em Mato Grosso e a região de fronteira entre o Brasil...

"continuador" do movimento de "30 de maio", 14 anos depois do evento. Ribeiro era acostumado a se opor tenazmente contra vários presidentes de província e lograva várias vitórias contra os chamados "delegados do Imperador", representantes do governo central, apesar das chamadas "leis centralizadoras" feitas principalmente na década de $1840 .{ }^{50} \mathrm{~A}$ ele cabiam várias acusações, desde reescravavização de pessoa livre a apropriação indevida de uma fazenda do governo, mas que nunca chegaram a prejudicálo efetivamente. Quando, por fim, o relacionaram aos terríveis assassinatos da "Rusga", seu grupo acabou promovendo uma festa - chamada de "orgia" pelas autoridades - justamente no aniversário do movimento ocorrido em Cuiabá, quando a maioria das pessoas estava enlutada, dizia um delegado.

Sobre a possibilidade de Ribeiro se mudar para a Bolívia, após pilhagem, provavelmente era um exagero do presidente Oliveira, que o tinha como grande rival. Eles acabaram se enfrentando nas eleições de 1849 para a Câmara Geral, na Corte. Finalmente, o fazendeiro de Poconé foi derrotado nas eleições em Mato Grosso, mas não totalmente. O governo central, depois do pleito, resolveu abrir uma segunda vaga. Ambos, então, foram para o Rio de Janeiro como deputados por Mato Grosso.

Certamente, a memória do que tinha sido o "30 de Maio", e outras rebeliões do período Regencial, assinalava o potencial explosivo também na província de Mato Grosso, cujo acesso demoraria meses de viagem para quem partisse do litoral. E foi depois desse movimento que se formaram os dois grupos políticos na província, ao mesmo tempo que antigas lideranças praticamente desapareciam da cena pública. A partir da década de 1850, há uma certa estabilidade na ocupação de cargos provinciais, o que acalmou ambos os partidos até a década de 1860. Mas os confrontos intraelites durante o Império não pareciam mais tão contundentes, e uma "repetição" do que acontecera em 1834 mostrava-se uma possibilidade extremamente remota. ${ }^{51}$

Quando foi assinado o primeiro acordo de limites entre o Brasil e a Bolívia, em 1867, um ponto era diretamente ligado à experiência de fugas de pessoas procuradas pela justiça, como foi o caso dos participantes do "30 de

${ }^{50}$ Sobre uma certa autonomia dos grupos locais frente às legislações que retirariam poderes regionais, ver SENA, E. C. Além de eventual substituto. A trama política e os vice-presidentes em Mato Grosso (18341857). Almanack, Guarulhos, n. 04, p. 75-90, 2ºmestre de 2012. Ver também DOLHNIKOFF, M. Entre o centro e a província: as elites e o poder legislativo no Brasil oitocentista. Almanack Braziliense, n. 1, maio de 2005.

${ }^{51}$ SENA, Ernesto Cerveira de. Desafios políticos nas fronteiras do Império: do discurso da ordem ao encalço da civilização em Mato Grosso (1834-1862). In: CRUZ, T. M. B. da; NEVES, L. M. B. P. das; PASCHOAL, L. M. (Org.). Elites, fronteiras e cultura do Império do Brasil. Rio de Janeiro: Contra Capa, 2013. v. 1, p. 57-73. 
maio" - que passavam de um a outro país -, e que estipulava a extradição de quem houvesse cometido crime, o que tinha causado tantos desentendimentos entre a província de Mato Grosso e o departamento de Santa Cruz. Como consequência, tal diretriz sobre "repatriamento" poderia diminuir tanto o repertório de especulações sobre evasão de membros das elites políticas, quanto as possibilidades dos que realmente procuravam evadir das penas em cadeias estipuladas pelos tribunais de seus países ${ }^{52}$.

A possibilidade de fuga para o país vizinho constitui apenas um dos aspectos da região de fronteira. Seria por essa região indefinida nas primeiras décadas dos Estados nacionais que deveria passar a linha divisória entre os novos países. Mas, antes disso, várias estratégias foram empregadas, como o acolhimento dos que queriam migrar. Tratava-se de uma estratégia, pois os dois novos Estados nacionais careciam de pessoas para povoar a região fronteiriça. Do mesmo modo, a recusa em extraditar indivíduos considerados criminosos também poderia ser trunfo em um futuro acordo entre os países.

Se, na linguagem diplomática, a Bolívia estava disposta a ajudar os que poderiam ser flagelados pelos revoltosos do "30 de Maio", ela também estava disposta a abrigar os próprios detonadores do conflito. Assim, as dimensões locais, nacionais e internacionais eram expressas na região de fronteira, sobre a qual os dois países procuravam ter controle, mas que se apresentava como lugar privilegiado para os que empreendiam fuga, podendo, inclusive, lá permanecer, ainda que fosse indefinidamente. A região fronteiriça, portanto, apresentava demandas próprias, influindo nas negociações internacionais e nas políticas de relacionamento entre governantes e elites locais.

Se o Império não possuía um projeto específico e coeso em suas relações externas até a segunda metade do século XIX, podemos dizer que existia um "pano de fundo" na política internacional boliviana e brasileira, que era ter elementos favoráveis à argumentação de posse territorial em áreas de litígio, já que os tratados metropolitanos não eram mais base segura. Para a Bolívia, voltada mais para o Pacífico, as condições se mostraram mais precárias para a territorialização da zona de fronteira se comparadas às do Império, que até mesmo travou uma guerra contra o Paraguai, sendo um

\footnotetext{
${ }^{52}$ Segundo Lema Garret, o Império do Brasil teria se apropriado de aproximadamente 400 mil quilômetros quadrados em relação aos que rezaria os antigos tratados coloniais, estipulado preliminarmente pelas coroas ibéricas. LEMA GARRET, Ana María. Frontera permeable y brazos apetecidos. La migración de los indígenas chiquitanos a Brasil a fines del siglo XIX. Ponencia presentada al $6^{\circ}$ Congreso de la AEB, Sucre, 2011.
} 
O “30 de Maio": uma rebelião em Mato Grosso e a região de fronteira entre o Brasil...

dos motivos o anseio de acesso perene aos rios platinos que ligavam ao interior do continente e, consequentemente, ao Mato Grosso que possuía vastas fronteiras. $\mathrm{E}$ foi somente depois desse conflito que a fronteira começou a ser mais bem delimitada, sem excluir a ideia de "região de fronteira", onde pessoas de nacionalidades ou etnias diferentes poderiam vislumbrar a mudança de seu status quo, a despeito dos acordos entre os novos Estados nacionais.

Artigo recebido para publicação em: 16/07/2013

Artigo aprovado para publicação em: 12/11/2013 